\title{
Candidate Profiles: 1986 MRS Officers and Councillors
}

The future growth of the Materials Research Society depends on the basic perceptions of Officers and Councillors of the Society and theirdedication to achieving their particular goals for the membership. As a member of MRS, it is your responsibility to voice your opinion concerning which people should

\section{Candidates for First Vice President (President-Elect)}

\section{Jagdish Narayan}

Microelectronics Center of North Carolina and North Carolina State University

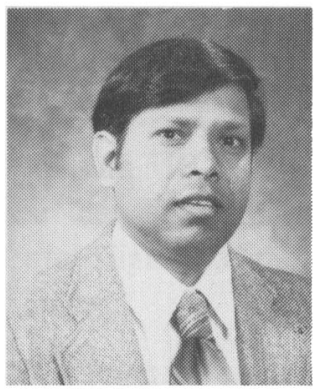

Jay Narayan received his BS in metallurgy in 1969 from the Indian Institute of Techology, and MS and PhD in materials science from the University of California at Berkeley in 1970 and 1971, respectively. At Berkeley, he also minored in solid state physics and electrical engineering. After a year at the Lawrence Berkeley National Laboratory, he joined Oak Ridge National Laboratory, where he was leader of the defects and interfaces/electron microscopy group in the Solid State Division. He was recently appointed director of materials research for the Microelectronics Center of North Carolina, and also is a senior professor of electronic materials at North Carolina State University.

Narayan, who became a naturalized citizen of the United States in 1981, is a fellow of the American Physical Society and the American Association for the Advancement of Science. He has received a number of awards, including the U.S. Department of Energy's Outstanding Sustained Research Award and three IR-100 Awards from Industrial Research. His research interests include defects in semiconductors, lasersolid interactions, and transient thermal fill these vital positions by casting your election ballot by September 27, 1985. Please review the following profiles of candidates running foe the offices of First Vice President (President-Elect), Second Vice President, and five seats on Council. The elected individuals will begin their terms of office in January
1986. Your ballot has been mailed to you separately. Look for it, complete it, and return it as soon as possible to the Materials Research Society, 9800 McKnight Road, Suite 327, Pittsburgh, PA 15237.

Woody White

Nominating Committee Chairperson

processing of materials, radiation damage in materials, electron diffraction and microscopy, and defects and physical properties of materials.

Narayan has served the Society in many capacities. In 1980, he initiated the symposium on Defects in Semiconductors, a series that has become among the most popular offered at MRS meetings. In 1982, he cochaired the symposium on Laser-Solid Interactions and Transient Thermal Processing of Materials, and in 1983 he helped organize the symposium on Defect Properties and Processing of High-Technology Nonmetallic Materials. He was a program chair of the 1984 MRS Fall Meeting and also served on the 1984 Membership Committee. Narayan currently serves as Councillor for the Society.

"Present and future advances in technology depend very much on the availability of novel and improved materials. The Materials Research Society is in a unique position to play an important role in bridging the gap between fundamental sciences and technological applications, which is critical for developing advanced materials. I would like to continue serving the Society in ways that will ensure that this important service to the scientific and technical communities continues to grow and respond to their needs, through more educational programs, expanded technical programming, and closer ties and cooperative exchanges with international scientific groups."

\section{Kathleen C. Taylor}

General Motors Research Laboratories

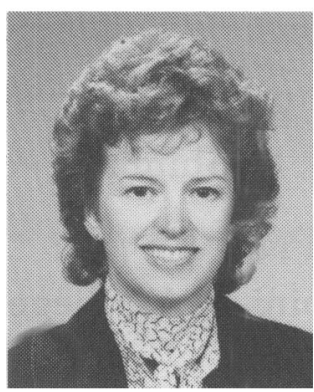

Kathy Taylor received an AB in chemistry from Rutgers University in 1964 and PhD in physical chemistry from Northwestern University in 1968. She joined GM Research Laboratories in 1970, where she is currently head of the Enviromental Science Department. Her research interests include heterogeneous catalysis, surface chemistry, and enviromental science. In addition to her long association with MRS, she is a member of the American Chemical Society, Society of Automotive Engineers, and Air Pollution Control Association.

Kathy Taylor's contributions to MRS are monumental and far-reaching. She is currently Second Vice President of MRS overseeing activities of the Education and Publications Committees. She is also a Councillor of the Society and a member of the Finance Committee. She served a fouryear tenure as MRS Treasurer (1980-84), and was responsible for the sound financial operation of the Society during a period of very rapid evolution and growth. She cochaired the symposium on Catalyst Preparation and Maintenance of Catalyst Activity at the 1979 Annual Meeting, where she also served as a program chair responsible for organizing the meeting. She served on the Select Committee which established the new MRS Headquarters. She was responsible for reviewing alternatives and means of implementing a permanent headquarters operation, and implemented the day-to-day financial operations at the newly established headquarters in 1983 . Taylor conceived and implemented the Graduate Student Award Program in 1980, which she managed through 1984.

"The major issue facing MRS now and in 1986 is the successful launching of Journal of Materials Research with the same unique qualities which have characterized MRS and led to its rapid growth. At the same time, we shall see an expanded short course program, an increase in Student Chapter and Local Section activity, and growth of international affiliations. I would like to see the Society continue to adapt its programs to the needs of the rapidly expanding materials science community. The Society's plans are ambitious and MRS leadership must carefully balance demands on resources to ensure cost-effective activities and services for the 
membership. I have enjoyed my long involvement with MRS. I thank the membership for its past support, and l look forward to working with MRS in the future."

\section{Candidates for Second Vice President}

\section{J. E. E. Baglin}

IBM T. J. Watson Research Center

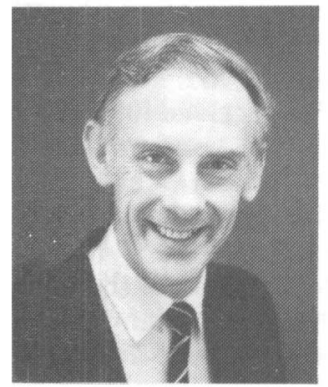

John Baglin received his $\mathrm{PhD}$ in physics from the University of Melbourne, Australia in 1963. From 1963-1965 and 19701972, he was assistant professor of physics at Iowa State University, where he was also associate physicist at Ames Laboratory. Between periods at lowa State, he was research associate at Yale University. Baglin has been with the IBM T. J. Watson Research Center, Yorktown Heights, New York, since 1972. His research interests include physics of thin film structure, interfaces and interactions; radiation effects in solids; ion beam and laser modification of materials; and ion beam analysis. He also holds strong interest in innovative teaching of science. He is a member of the American Physical Society, Sigma $X_{i}$, and councillor of the Böhmische Physical Society.

Baglin has been a member of MRS since 1978 , serving in a number of capacities. He was chairperson of the 1984 Publications Committee and chairs the 1985 Subcommittee on Book Publishing. During these two years, he worked to establish the inhouse proceedings publishing operation at MRS Headquarters, which will result in the timely and cost-effective publication of 15 volumes in the MRS Symposia Proceedings series by the end of the year. He was also involved in establishing the Journal of Materials Research, which will debut in early 1986 . He is a member of the 1985 Program Committee and serves as meeting chair for the 1985 Fall Meeting, responsible for organization of this meeting. He chaired the 1983 symposium on Thin Films and Interfaces, served as editor of the resulting proceedings, and has been active in the Publications Committee since that time.

"MRS is experiencing a period of dynamic growth and excitement - enlarged membership and meeting attendance, more meetings, new international and regional chapters, thriving short courses and equip- ment shows, a powerful in-house publishing operation for the Proceedings and the fast-expanding MRS BULLETIN, and now a definitive archival Journal of Materials Research. A spirit of innovative thought and action, creative independence, willingness to accept startling challenges and try fresh ideas, has been the key to MRS' unique success and appeal. As we continue to develop, we must keep the attitude and spirit of the bold new enterprise - energetic, adaptable, looking always to the future. MRS must vigorously support Journal of Materials Research to ensure that it earns rapid acceptance as a journal of high standards and extensive readership. It must expand its independent sources of income which can be applied to costs of meetings, to management of MRS operations, and to programs such as student awards. Such income may be derived from corporate contributions, publishing operations, short courses, equipment shows, advertising, etc. We must also plan ahead to add one or perhaps two new major meetings to the yearly roster and consider their best locations. Our Spring and Fall Meetings alone, in fixed locations, cannot satisfy the expanding MRS needs."

\section{Paul S. Peercy}

Sandia National Laboratories

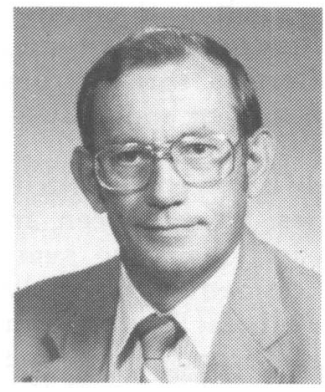

Paul Peercy is manager of the Ion Implantation and Radiation Physics Research Department at Sandia National Laboratories in Albuquerque, New Mexico.

After receiving his $\mathrm{PhD}$ in physics from the University of Wisconsin in Madison in 1966, Paul joined AT\&T Bell Laboratories; in 1968 he joined the technical staff at Sandia. His research programs have included the physics of semiconductors, plasmas in solids, structural phase transitions and ferroelectricity, Raman and Brillouin scattering in solids, ion implantation, ion beam analysis and laser materials processing.

Paul has been active for several years in the Materials Research Society, both as a participant and as a leader of the organization. He was co-organizer of the 1979 MRS symposium on Laser and Electron Beam Processing of Materials and served two years as a member of the MRS Membership Committee. He was a chairperson for the 1984 Fall Meeting with responsibility for the organization of that highly successful meeting. He currently chairs the Program Committee. In addition, he has been selected as one of the Principal Editors of Journal of Materials Research, scheduled to begin publication in 1986 .

"The Materials Research Society has an important role to fill in providing a forum for scientists, engineers and technologists from different disciplines to discuss forefront topics of common interest. Because of its interdisciplinary nature, the Materials Research Society plays a unique role that is necessary to permit its members to keep pace with the rapid advances in technology, and it is imperative that the Society retain the spontaneity and flexibility that has permitted it to move rapidly into new materials research areas as the need arises."

\section{Candidates for Councillor}

\section{(five to be elected to three-year terms)}

\section{Robert W. Balluffi}

Massachusetts Institute of Technology

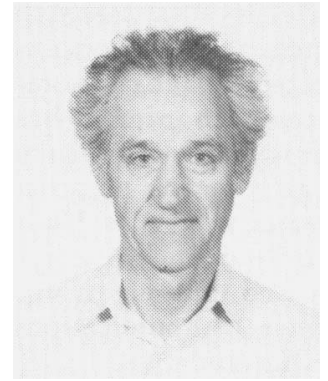

Dr. Balluffi received both his BS (1947) and ScD (1950) from MIT. From 19501954, he was senior research engineer for Sylvania Electric Company Research Laboratory, and then joined the faculty of the University of Illinois where he served for 10 years as assistant professor of physical metallurgy, associate professor and then professor in the Department of Mining, Metallurgy and Petroleum Engineering. From 1964-1978, he was Francis Norwood Bard Professor in the Department of Materials Science and Engineering at Cornell University, and became head of the department in 1974. Balluffi is currently professor of physical metallurgy, Department of Materials Science and Engineering at MIT. $\mathrm{He}$ is a member of the National Academy of Sciences, and Fellow of the American Academy of Arts and Sciences, The Metallurgical Society of AIME, and the American Physical Society. He is a recipient of the R. F. Mehl Medalist and Institute of Metals Lecturer Award from AIME (1982) and is author of 170 papers in the areas of crystal defects, diffusion, and radiation damage. He is the author of the paper "Interactions Between Lattice Dislocations and Interfaces in Solids," which was presented at the 1983 MRS Fall Meeting.

"My major general interest is in establishing materials science and engineering as a coherent and well-organized discipline covering all major types of materials. Special effort is also needed to foster beneficial interactions between MRS and academia and to achieve an optimum balance between basic and applied research interests within MRS." 


\section{R. P. H. Chang}

\section{ATET Bell Laboratories}

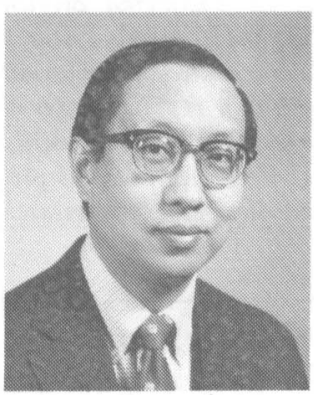

Bob Chang grew up in China and spent 10 years in Japan prior to coming to the United States. He received his BS from MIT and PhD from Princeton University. In 1971, he joined the research division of AT\&T Bell Laboratories to start research in experimental plasma physics, concentrating on nonlinear plasma wave phenomena. Since 1976, his research interest has shifted toward the study of plasma-solid surface interactions as a means of processing thin film electronic materials. He is currently actively working on electronic materials for integrated optoelectronic devices. Chang has over 170 publications (including patents) to his credit.

Chang has been very active in MRS in various capacities. In 1984, he organized the first symposium on Plasma Synthesis and Etching of Electronic Materials and obtained 16 corporate sponsors to support the symposium. He has been appointed Meeting Chair of the 1986 MRS Fall Meeting, along with Jim Roberto and Carol Janzten, with responsibility for the organization of this meeting. Earlier this year, he was appointed Chairman, International Relations, responsible for encouraging MRSstyle activities around the world. $\mathrm{He}$ is currently working with scientists in Asia to plan a meeting in 1988 which would include MRS participation. Chang is also an active member of the Program, Awards, Long Range Planning, and Corporate Participation Committees.

"As a member of Council, I will work actively to develop international activities in Asia and Australia, as well as in Europe and North America. I will seek to establish Journal of Materials Research as the premier archival medium for publication of interdisciplinary results. I am very much in favor of an increased utilization of MRS Headquarters, so that the rapid and orderly growth of the Society can be assured. I' will strongly encourage increased university faculty and student participation in the Society, and I favor an expanded role for MRS to act as a catalyst for increased cooperation between industry and universities in the areas of materials research and development."

\section{Wei-Kan Chu}

University of North Carolina

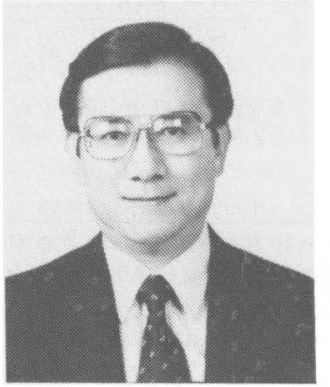

For the last four years, Wei-Kan Chu has been professor of physics at the University of North Carolina-Chapel Hill, where he initiated a research program on the application of ion beams to electronic materials characterization and modification. Chu is a graduate of Chung-Kung University and received his $\mathrm{PhD}$ in physics from Baylor University in 1969. He did post-doctoral research at Baylor and Caltech, and then joined IBM in Fishkill, NY for six years, as an engineer and then senior engineer. He joined the faculty of the University of North Carolina in 1981. Chu is the author of more than 120 papers and four patents, and his research interests spread from basic ion-solid interaction to applied materials science.

He has been actively involved in MRS in a variety of capacities. He has been an invited speaker, session chair and symposium chair, and is President of the newly formed North Carolina Local Section. Chu is currently serving his second year on the Publications Committee and is one of the Meeting Chairs in charge of organizing the 1986 Spring Meeting in Palo Alto, CA

"I welcome the opportunity to serve on the Council and help MRS fulfill two of its important missions. First, on a national level, MRS is in a unique position to foster and strengthen a close collaboration between government, industry, and institutes of higher learning. This stimulating interaction could be brought about through the creation of an MRS center dedicated to the testing of new concepts in materials science and engineering as well as to helping individual researchers with problems of technology transfer

"Second, at the international level, we have witnessed the emergence of MRS into a strong multinational society. 1 would like to emphasize a close collaboration among materials scientists of different countries; joining forces to explore and share our creative insights would help bring our understanding to deeper levels.

"The social implications of materials research are numerous and important. I believe that we will all benefit from sharing and working together."
James W. Corbett

State University of New York-Albany

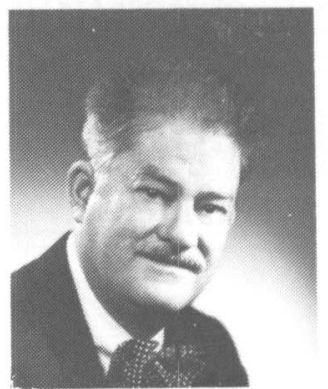

Prof. Corbett received his BS in physics with distinction from the University of Missouri at Columbia in 1951, and his MS from there in 1952. He received his $\mathrm{PhD}$ in physics from Yale in 1955. After a brief stint in the Chemistry Department at Yale, he joined the GE Research Laboratory, where he remained until 1968, when he joined the Physics Department of the State University of New York at Albany where he was chair from 1969 to 1970 . In 1981 he was appointed Distinguished Service Professor of the State University of New York, but he remains based at Albany. He is adjunct professor at the Center for Integrated Electronics at Rensselaer Polytechnic Institute, where he also lectures and does research. He has been a National Academy of Sciences Exchange Lecturer to the USSR, Distinguished Visiting Professor at the American University of Cairo and the École Normale Supérieure and University of Paris (VII), and a Senior Fulbright Lecturer at the University of Tbilisi, USSR. He is a fellow of the American Physical Society, a senior member of the IEEE, and a member of the Electrochemical Society, the American Association of Physics Teachers, and MRS.

He has written or edited six books or proceedings, written 26 survey articles and over 150 journal articles, all primarily on defects in semiconductors and metals. He is the debate editor of Diffusion and Defects Data, and associate editor of Materials Letters, and serves on the Editorial Advisory Boards of Radiation Effects and Crystal Lattice Defects. He has helped to organize two Materials Research symposia and currently serves on the Publication Committee of the Materials Research Society.

"The great virtue of the Materials Research Society, in my view, is the vitality, vigor, and freshness in its service to its constituent professions. I pledge myself to trying to continue that young, but well-established, tradition." 


\section{Frank Y. Fradin}

Argonne National Laboratory

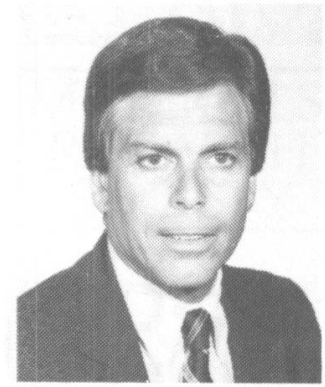

As director, Materials Science and Technology Division at Argonne National Laboratory, Frank directs a research staff of over 200 in areas of advanced materials (including layered and thin films, organic conductors, complex oxides, glasses, superconductors, and magnetic materials), surface science and corrosion (including heterogeneous catalysts, high temperature aqueous corrosion, and ion surface interactions), defects and radiation effects (including ion and neutron damage, ion beam surface modification, and solid-state processed amorphous alloys), and materials technology (including materials for fission, fusion, fossil and fuel cell technologies). His own research has primarily focused on superconducting and magnetic properties of materials. Fradin is a member of the Editorial Board of the MRS BULLETIN and a fellow of the American Physical Society.

"The Materials Research Society has a number of opportunities to address important national issues in the next few years. One that I feel is deserving of great attention is the development of an integrated materials research funding strategy for the various federal agencies. This strategy would encompass the large financial commitments to facilities such as neutron sources, synchrotrons, and advanced electron microscopes. Because of its broad representation from the ind ustrial, academic, and government laboratory sectors, MRS has an opportunity to properly influence such a national materials research strategy."

\section{Noble M. Johnson}

Xerox Palo Alto Research Center

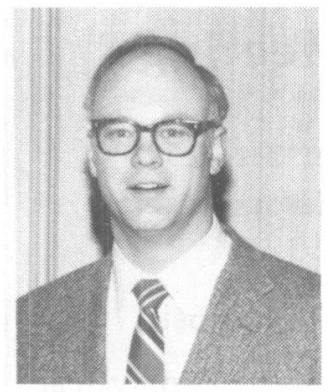

Noble Johnson received his PhD from Princeton University in 1974. From 19741976, he was a member of the Radiation Physics Group at SRI International in Menlo Park, California. Since 1976 he has been with the Xerox Palo Alto Research Center, where he is currently a senior member of the research staff. His research has focused on electronic properties of materials and devices, with emphasis on defects in semiconductors. Recent research activities include laser-crystallized silicon thin films, characteristic defects at the Si$\mathrm{SiO}_{2}$ interface and in a-Si:H, and hydrogen passivation of shallow-acceptor impurities in semiconductors.

Johnson has been active in the Materials Research Society since the first symposium on laser annealing held in 1978. At the 1983 MRS Annual Meeting, he co-chaired the highly successful symposium on Energy Beam-Solid Interactions and Transient Thermal Processing. Last year he served as a meeting co-chair for the Society's first Spring Meeting in Albuquerque, New Mexico. At the second Spring Meeting, held last April in San Francisco, he cochaired the symposium on Microscopic Identification of Electronic Defects in Semiconductors. Participants of this symposium have commented on the uniformly high quality of the invited and contributed presentations and, particularly, on the effectiveness of scheduling informative reviews on a broad range of experimental and theoretical techniques within the same symposium.

"Through my involvement with MRS over the past eight years, I have experienced first-hand the spectacular growth of the Society. This success is principally a consequence of three features of MRS: (1) the explicitly instituted interdisciplinary nature of the Society; (2) the emphasis on the exchange and dissemination of technical information; and (3) the ability and courage of the Society to systematically identify and sponsor symposia on topics at the forefront of materials science and technology. As a member of Council, I would strive to sustain our success as a technical society by promoting these features as the essence of the Materials Research Society and by continuing to contribute to their implementation."

\section{Robert A. Laudise}

\section{ATET Bell Laboratories}

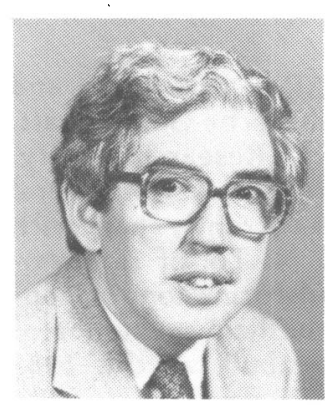

Robert A. Laudise is a graduate of MIT with a PhD in inorganic chemistry. He has been head of the Crystal Chemical Research Department, assistant director, and director of the Materials Research Laboratory, and presently director of the Physical and Inorganic Chemistry Research Laboratory at AT\&T Bell Laboratories. His research interests include electronic materials, materials conservation, crystal growth, high- pressure synthesis, and piezo-electric, magnetic, semiconductor, and nonlinear optical materials.

Laudise served as co-president of the American Asociaion for Crystal Growth, president of the International Organization for Crystal Growth, and chairman of the American Chemical Society Subdivision of Solid State Chemistry. He is an editor of the Journal of Crystal Growth, the book, The Growth of Single Crystals, and over 120 publications. He is a recipient of the Sawyer Prize, and the American Association of Crystal Growth International Prize, and is a member of the National Academy of Engineering. He was one of the founders of the Materials Research Society and has organized symposia at MRS meetings.

"Materials science and engineering is the cornerstone of the information society. In terms of both intellectual content and relevance it is one of the most exciting areas in modern science. MRS should continue to lead in shaping the directions, enlarging the interdisciplinary nature of the field and improving its prestige. In the future, industrial productivity, national competitiveness and progress in electronics, energy, transportation, prosthesis and environmental improvement will all be rate limited by materials progress. MRS should focus additional scientific and societal attention on these areas. Materials is a great field and MRS is a great society. I'd like as many people as possible to know it."

\section{G. J. McCarthy}

North Dakota State University

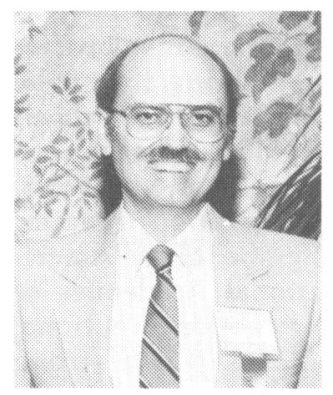

Greg McCarthy is professor of chemistry and geology at North Dakota State University in Fargo. Prior to coming to NDSU, he was a research associate professor at Penn State's Materials Research Laboratory. His office was next to that of one of the founders of MRS and just above its first Executive Secretary, so he literally watched the Society grow around him. He became especially active in 1978 while initiating the symposium series, Scientific Basis for $\mathrm{Nu}$ clear Waste Management, and editing its first proceedings. McCarthy was an MRS Councillor in 1979 and 1980. After helping out with the Nuclear Waste symposium for several more years, he turned his attention to another waste problem-coal ash. He has co-chaired and edited the proceedings of the last three symposia on Coal Ash Characterization, Utilization and Disposal. His editing experience also includes four volumes of the proceedings of the Rare Earth Research Conference and Advances 
in X-Ray Analysis. Greg is a member of ACS, ACerS, MSA, AAAS, and ACA, and is currently serving as chairman of JCPDSInternational Centre for Diffraction Data. He has developed several workshops on $x-$ ray diffraction analysis now offered throughout the world.

"I would be pleased to serve once again on the MRS Council. I would bring considerable experience in publications, symposium organization and nonprofit scientific society management. During my 12 years as a volunteer director and chairman of the JCPDS, I have had leadership responsibilities in technical development, industrial education programs, organizing volunteers, bylaws, budget development and implementation, and personnel management. Experiences such as these should be useful at this time of growth and stabilization of the MRS. I am also interested in seeing that there continues to be representation for the full range of 'materials' in its broadest sense at future MRS meetings."

\section{Rustum Roy}

Pennsylvania State University

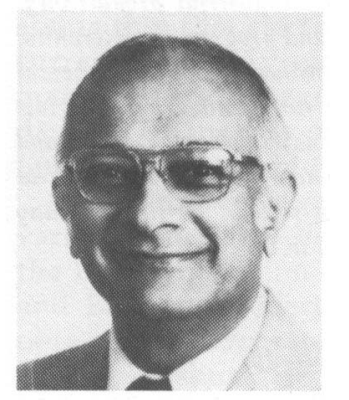

Rustum Roy is a crystal chemist, professor of the Solid State, and director of the Materials Research Laboratory at Pennsylvania State University. He is the author of 400 papers and four books on synthesis, preparation, and characterization of ceramic materials, and is a member of the American and Swedish National Academies of Engineering. He is very active in national sciences policy activities and is a strong advocate of interdisciplinary, universityindustry cooperation, and applied research in general.

Roy's association with MRS began at the Society's inception. He convened the early meetings of the Founding Committee and served as the Society's first Secretary and as its second President. The first Annual Meeting of the Society was held at Penn State in 1975, and the Society was headquartered at the Materials Research Laboratory, where Roy directed its operation for 10 years. He has organized many symposia at MRS meetings and annually runs the popular cross-disciplinary Symposium $X$ at both the Fall and Spring Meetings. He has also served on many MRS committees, including the Education, Nominating, and LongRange Planning Committees. He is also a member of the Editorial Board of MRS BULLETIN.

"We have succeeded in establishing MRS as the premier society devoted to materials research because we maintained, against great odds, our commitment to interdisciplinarity in three dimensions: across academic disciplines, across classes of materials, and across basic/applied sciencelengineering. We succeeded because we remained flexible and innovative and because this attracted many very talented people to work extremely hard for the Society. The worst thing we can do is rest on our laurels. Constant vigilance and conscious attention is the price of maintaining interdisciplinarity in a rigidly disciplinary world. The goals that I would work to achieve on the Council are (1) to establish Journal of Materials Research as the premier journal in materials (2) to establish a major and proactive role for MRS in national policy matters, and (3) to encourage the Society to serve as a more effective bridge-builder between universities and industry, in order that they may together be effective in maintaining a healthy economy."

\section{Frans Spaepen}

Harvard University

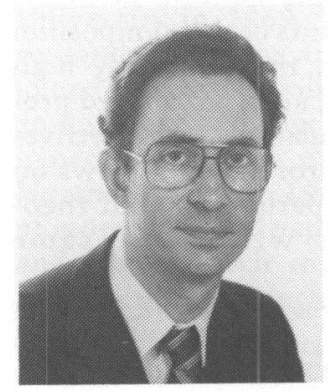

Frans Spaepen is Gordon McKay Professor of Applied Physics at Harvard University. He received his undergraduate degree in metallurgy from the University of Leuven, Belgium, in 1971, and his PhD from Harvard University in 1975. He joined Harvard as an IBM Research Fellow until 1977 , and has been a faculty member since then. His research interests include phase transformations involving amorphous metals and semiconductors, formation of new materials with pulsed laser quenching, interdiffusion and stability in amorphous multilayered films, structure of amorphous-crystalline interfaces and of grain boundaries, and mechanical properties of amorphous metals.

He is a member of AIME, ASM, APS, and the Böhmische Physikalische Gesellschaft, as well as the Materials Research Society. He has been an invited speaker at several MRS symposia, and is currently chair, with G. S. Cargill and K. N. Tu, of the symposium on Phase Transformations in Condensed Systems, to be held, in honor of Professor David Turnbull, at the 1985 MRS Fall Meeting.

"The MRS has been remarkably successful in bringing together the various disciplines that contribute to materials science in the broad sense. My own research interests are very much coincident with those of the Society. In fact, no other Society's annual meeting covers more of my activity than MRS'. I would like to see this type of interaction continue to develop, and as a Councillor I would work to foster ongoing Society responsiveness to new materials areas and to encourage the continued expansion of its education programs and international reach."

\section{J. Francis Young}

University of Illinois at Urbana-Campaign

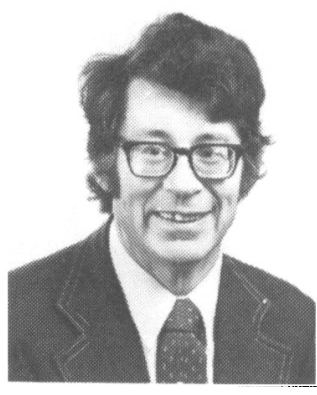

Francis Young is professor of civil engineering and ceramic engineering at the University of Illinois at Urbana-Champaign and holds $\mathrm{a} \mathrm{PhD}$ in inorganic chemistry from Imperial College, London. He is a fellow of the American Ceramic Society and serves as the representative of the Cements Division on the Board of Trustees.

Young co-chaired the symposium on Very High Strength Cement-Based Materials at the 1984 Fall Meeting. He was an invited speaker at the 1982 Fall Meeting, where he discussed the effect of surface properties and colloid phenomena on the properties of fresh concrete. He is currently a member of the Corporate Participation Committee, responsible for nurturing communication between the Society and research and industry.

"From the beginning of my association with MRS, I have been impressed with the dynamism of the Society and its catholic approach to materials. My concerns, if elected Councillor, will be to preserve these vital attributes in the face of the growing pressures of success. I would also like to foster further interactions between different interest groups, both within MRS through joint symposia and other forums, and through cooperation with other societies."

\section{REGISTER EARLY}

\section{MRS Fall Meeting}

\author{
December 2-6, 1985 \\ Boston, Massachusetts
}

- 20 technical symposia

- Over 10 displays of analytical and processing equipment

Look for registration information in the mail. 


\section{MATERIALS \\ RESEARCH \\ SOCIETY}

\section{PROCEEDINGS}

\section{MRS FALL MEETING}

Be sure to order your copies of the proceedings of this landmark meeting of the Materials Research Society.
Proceedings

A Energy Beam-Solid Interactions and Transient Thermal Processing/1984

C Impurity Diffusion and Gettering in Silicon

D Layered Structures, Epitaxy and Interfaces

F Plasma Synthesis and Etching of Electronic Materials

G High-Temperature Ordered Intermetallic Alloys

J Electronic Packaging Materials Science

K Advanced Photon and Particle Techniques for the Characterization of Defects in Solids

L Potential for Very High Strength Cement-Based Materials

M Coal Combustion and Conversion Wastes: Characterization, Utilization and Disposal

N Scientific Basis for Nuclear Waste Management VIII

Extended Abstracts

B Laser Chemical Processing of Semiconductor Devices

I Graphite Intercalation Compounds

O Alloy Phase Diagrams

P Fractal Aspects of Materials: Metal and Catalyst Surfaces, Powders and Aggregates
Member Price List Price U.S. Foreign

$\begin{array}{lll}\$ 36 & \$ 50 & \$ 55 \\ \$ 25 & \$ 36 & \$ 43 \\ \$ 36 & \$ 50 & \$ 55 \\ \$ 30 & \$ 43 & \$ 52 \\ \$ 30 & \$ 43 & \$ 52 \\ \$ 25 & \$ 36 & \$ 43\end{array}$

$\$ 30 \$ \$ 4$

Prepayment is required on all book orders (includes postage and handling). Send orders to Publications Department, Materials Research Society, 9800 McKnight Road, Suite 327, Pittsburgh, PA 15237, telephone (412) 367-3012.
AG Associates

Air Products and Chemicals ALCOA Allied Corporation American Microsystems, Inc. Applied Materials

ARCO Metals Company ARCO Solar, Inc.

AT\&T Bell Laboratories

AT\&T Technologies, Inc.

Blake Industries, Inc. Branson, IPC

Brimrose Corporation of America

Brush Wellman, Inc.

Cabot Corporation

Cameca Instruments, Inc.

CEMCOM Research Associates CILAS Alcatel

Combustion Engineering, Inc.-Power Systems Denton Vacuum, Inc Drytek, Inc.

E. I. du Pont de Nemours \& Company DynaVac

Eastman Kodak Company Eaton Corporation

ELKEM Chemicals, Inc.

Elsevier North-Holland

Energy Conversion Devices, Inc.

Charles Evans \& Associates

Exxon Research and Engineering Company Ferranti, plc GCA Corporation

General Electric Ceramics, Inc.

General Electric Company

General Ionex Corporation

General Motors Research Laboratories GTE Laboratories Harshaw/Filtrol Helionetics

High Voltage Engineering Europa B.V. Hirst Research Centre

Hitachi Scientific Instruments

Hughes Aircraft Company

Imperial Chemical Industries, plc

Instruments SA, Inc.

International Business Machines Corporation JEOL USA Lam Research

Lambda Physik

Lanxide Corporation Lasertechnics

Lawrence Livermore National Laboratory Leybold-Heraeus LFE Corporation

Los Alamos National Laboratory Lumonics 3M Company

Martin Marietta Laboratories

Materials Research Corporation Microscience, Inc. Monsanto

National Electrostatics Corporation

Newport Corporation Perkin-Elmer

Philips Electronic Instruments, Inc.

Plasma-Therm Systems, Inc.

Portland Cement Association

Quantronix Corporation Questek, Inc.

Sandia National Laboratories

Schlumberger-Doll Research

Schott Glass Technologies, Inc.

$$
\text { L. M. Simard, Inc. }
$$

SOHIO Chemicals \& Industrial Products Company

Solar Energy Research Institute

$\$ 5 \quad \$ 7$

Spectra Physics

Spire Corporation

Standard Oil of Indiana

Stauffer Chemical Company

Surface Science Laboratories, Inc.

Tegal Corporation

$$
\text { TRW }
$$

Union Carbide Corporation United Technologies Research Center UOP

Varian/Extrion

VG Instruments, Inc.

W. R. Grace \& Company

Westinghouse Electric Corporation

Xerox Corporation

XMR

Zymet 